\title{
Thermal treatment of desert sand to produce construction material.
}

\author{
Frank Neumann ${ }^{1}$, Manfred Curbach ${ }^{2}$ \\ ${ }^{1,2}$ Technische Universität Dresden, Institute of Concrete Structures, Dresden, Germany
}

\begin{abstract}
The concrete and reinforced concrete industry has refrained from using desert sand. The reasons for this are the rounded form of the particle, its grading and its chemical composition. This article provides an overview of the background, the constructability and technological challenges that the construction industry faces regarding construction sand's shortage. Also, construction aggregates consumption and its influence on fresh and hardened concrete properties are described. The paper concludes by presenting several feasible approaches and provides a feasible technological solution.
\end{abstract}

\section{Demand for construction aggregates}

The most common construction material in the world is concrete. About 8 billion $\mathrm{m}^{3}$ of concrete were produced in 2015 [1]. This means that nearly 5 billion tons of the fine aggregate fraction, denominated as sand was consumed for concrete construction in 2015. In Germany, the consumption is estimated at 253 million tons of sand and gravel [2] per year. In addition to its use as a construction material, sand is often used for artificial land reclamation, especially in China, Singapore and the United Arab Emirates (UAE). The worldwide amount of sand used, along with concrete production included is calculated between 15 and 40 billion tons per year [3, 4].

\section{Aggregates for concrete casting}

The shortage of construction sand, the economic disadvantage of sand imports and the regional unavailability of sufficient construction sand had led several researchers involved in concrete and mortar production to investigate the feasibility of substituting fine aggregates by desert sands.

Concrete consists of $20 \%$ water, cement and $80 \%$ aggregates. Aggregates with different diameters (Figure 1) are chosen for concrete production to achieve a stable granular structure. The appropriate selection of the material is important especially for fresh concrete as it prevents aggregate separation and sedimentation. To reduce the amount cement and water needed, to minimize pores and to reduce shrinkage and the risk of carbonation of the hardened concrete [5], appropriate grain curve has to be chosen. Because of this, nearly a third up to a half of the used aggregates have a maximum diameter of $2 \mathrm{~mm}$. Figure 1 compares different packing rates and illustrates the effect of stabilization by using different grain sizes for concrete production.
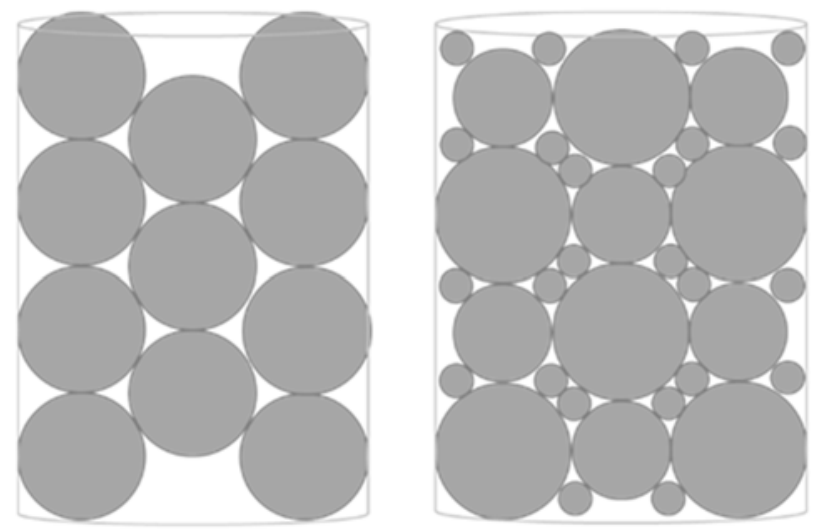

Fig. 1: Structures packed with different tightness to ensure stability within fresh concrete: homogeneous (left) and poorly graded grain (right). (Graphic: F. Neumann)

The specific surface and the shape of aggregates influence the water consumption and workability of fresh concrete. For this reason, the above-mentioned grain curves and aggregates with corresponding surface and shape have to be chosen according to the requirements and properties of the concrete. Desert sand grains are mostly distributed in a monomodal manner. This means grains with one specific diameter are dominating. Thereof only a single fraction of fine aggregates in the ordinary concrete mixture can be substituted to obtain the required grading curve. The shape of desert sand grains, in comparison to aqueous grains, is mostly round. It is caused by aeolian transport effects and varies from equant over elongated to flaky and between very angular and well-rounded. This affects the mechanical interlock between aggregates and thereof the stability of the mixture as well as fresh concretes properties. 


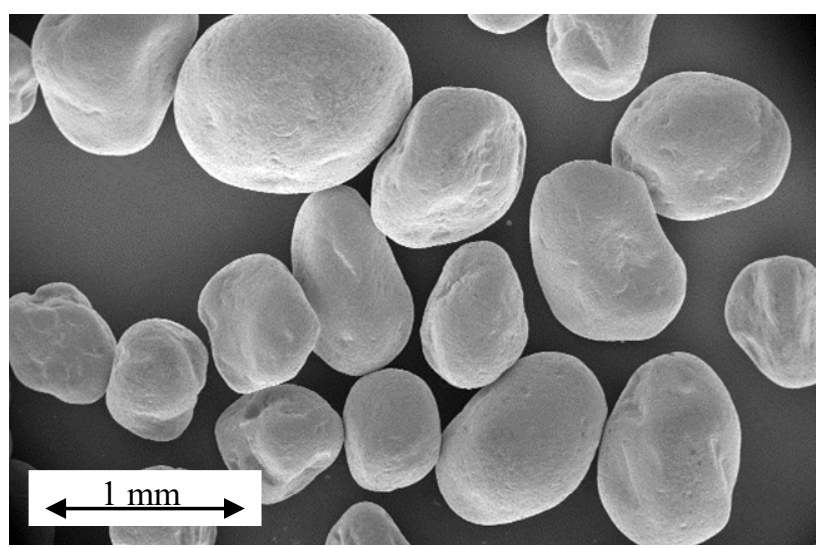

(a) $0.5 \mathrm{~mm}$ to $1.0 \mathrm{~mm}$ fraction from Libya.

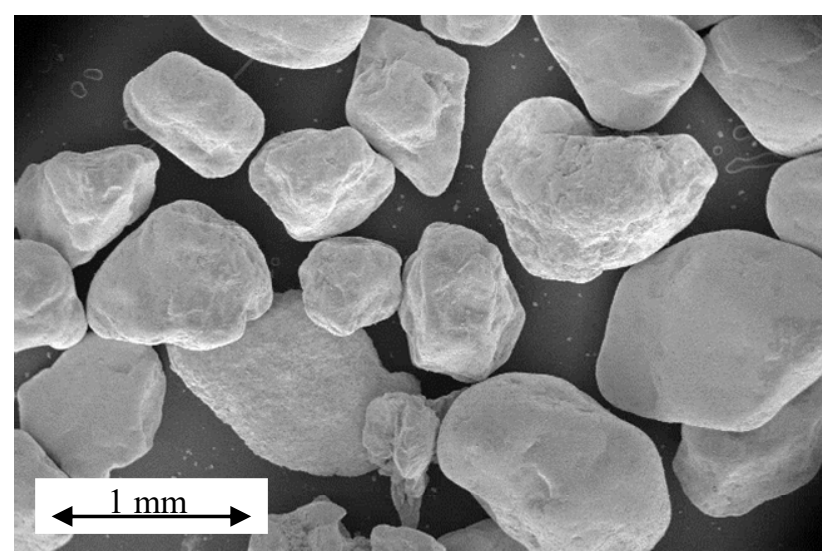

(b) $0.5 \mathrm{~mm}$ to $1.0 \mathrm{~mm}$ fraction from Algeria.

Fig. 2: ESEM analysis of desert sand grains. (Photos: Simone Hempel, TU Dresden)

Up to a certain extent, the workability is improved with benefits to sedimentation. Figure 2 a shows wellrounded desert sand grains from Libya with a diameter between $0.5 \mathrm{~mm}$ and $1.0 \mathrm{~mm}$ studied via environmental scanning electron microscopy (ESEM). Figure $2 b$ shows grains with the same diameter from Algeria with a slightly edged shape and thereof a higher surface. Concrete properties are also affected by desert sand's chemical composition. The solubility of certain salts contained in aggregates and cement phases depend on the $\mathrm{pH}$ value of the pore solution which is affected by adsorption and desorption of dissolved carbonates, chlorides and sulfates [6]. On the one hand, dissolved chloride ions are leaching the portlantide. On the other hand, chloride or sulfate ions that are present dissolute in the mixing water and react with the tricalcium aluminate to give Friedel's salt and the ettringite, respectively [7].

Some researchers investigated concretes made with desert sand aggregates and compared the mechanical properties with those of standard concrete. Although the workability was improved and the variation in air content was negligible while w/c-ratio was constant, a reduction in compressive and tensile strength of $16 \%[8,9,10]$ was found. Depending on the substituted amount of fine or very fine aggregates, a reduction of about $21 \%$ was measured. By substituting $100 \%$ of the fine aggregates with dune sand, the compressive and tensile strength of selfcompacting concrete (SCC) were reduced to $50 \%$ compared to an SCC made of crushed sand [11].

Another approach to meet the challenge of a construction sand shortage comes along with the idea of reducing the needed amount of concrete to prevent steel reinforcement from corrosion. The layers of concrete surrounding the steel are thicker than statically necessary. The objective of the new material called carbon reinforced concrete, based on substitution of common steel reinforcements with carbon fiber reinforcements, is to reduce the amount of concrete and thereof the amount of cement $[12,13,14]$ and aggregates. Along with that, the concrete composition has to be adjusted in order to meet the requirements of carbon reinforced concrete. Typical mesh sizes of textile reinforcements are between $10 \mathrm{~mm}$ and $14 \mathrm{~mm}$ which prevent ordinary aggregates from penetrating trough the grid. Mostly, the used concrete is based on a grain curve with a maximum grain size of $2 \mathrm{~mm}$.

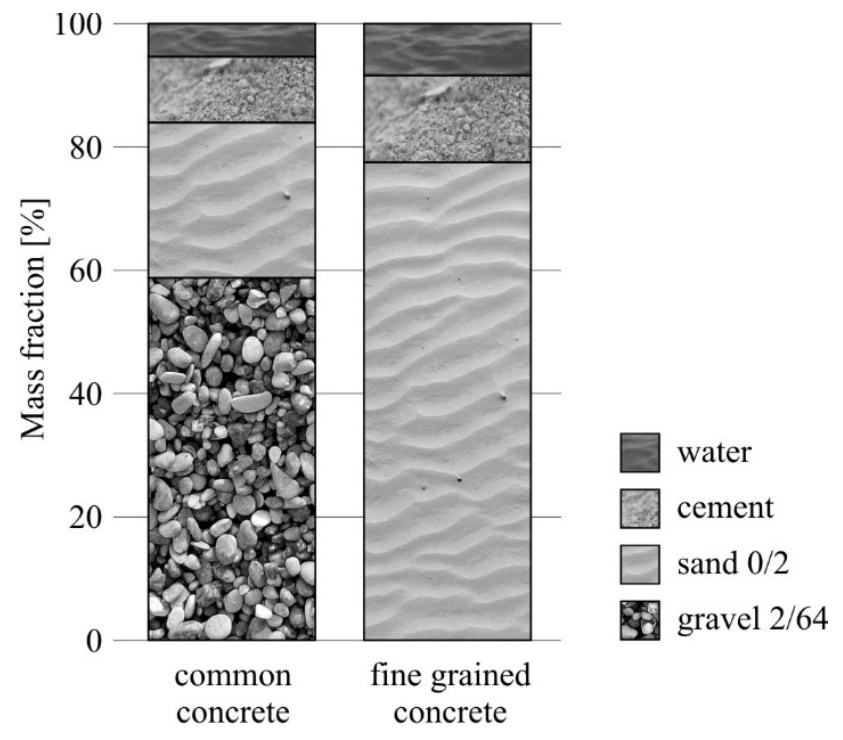

Fig. 3: Comparison of mass fractions between common concrete and fine aggregate concrete. (Graphic: F. Neumann)

In Figure 3, a common concrete mixture for steel reinforced concrete with a maximum grain size of $63 \mathrm{~mm}$ is compared to an optimized fine graded concrete mixture for carbon fiber reinforcements with a maximum grain size of $2 \mathrm{~mm}$. The substitution of $20 \%$ of common steel reinforced concrete with carbon fiber reinforced concrete will consequently raise the overall consumption of fine aggregates by about 1 billion tons per year.

However, the substitution of fine aggregates by desert sand comes along with a loss in strength which is acceptable in an economical point of view unless the strength does not fall below a certain value. Nevertheless, most previous studies focus on fine or very fine grains only. Shape as well as chemical composition mostly remain unconsidered although they are affecting fresh and hardened concrete and are varying from deposit to deposit even among single grain sizes. 


\section{Approaches for a technical solution}

In the past, some technical solutions where developed to modify or reshape desert grains in order to substitute concrete's ordinary aggregates. These technical approaches are mainly based on a melting process followed by a crushing process $[15,16]$ or on pre-shaping the aggregate with a high voltage electrostatic field [17].

One of the challenges of the 21 st century is the construction of buildings on celestial bodies. At this moment the use of local available resources is essential. Several investigations focused on the available aggregates on the moon, called regolith. Such an aggregate compares well with terrestrial ashes [18] with grain sizes between $0.05 \mathrm{~mm}$ and $0.1 \mathrm{~mm}$ [19]. Lunar base construction materials may be produced by direct sintering of the regolith [20].

The method, patented by Technische Universität Dresden [21], is based on the same process which allows the reshaping of solids by combining single particles (Figure 4). The sintering process, which is known in the field of powder metallurgy, connects two or more particles with each other without melting them.

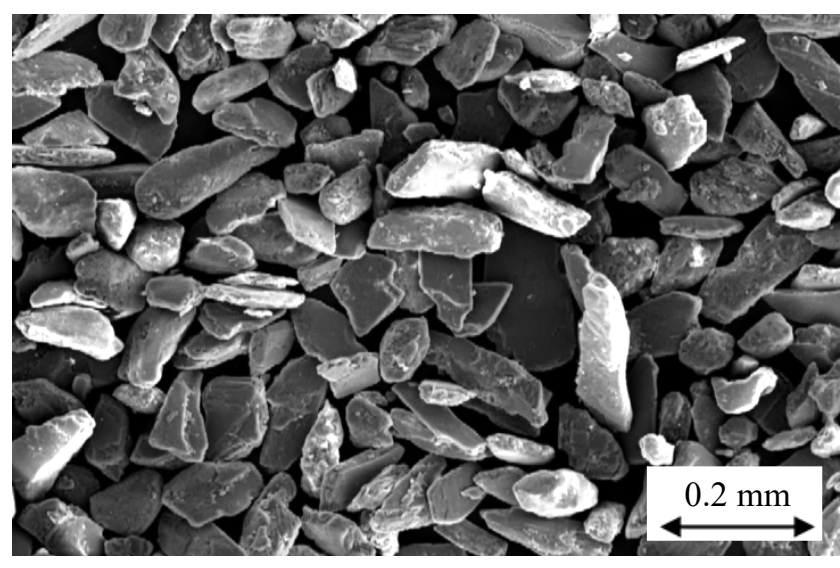

(a) Sample I: Sieved grains from Namibia with a diameter between $0.5 \mathrm{~mm}$ and $1.0 \mathrm{~mm}$.

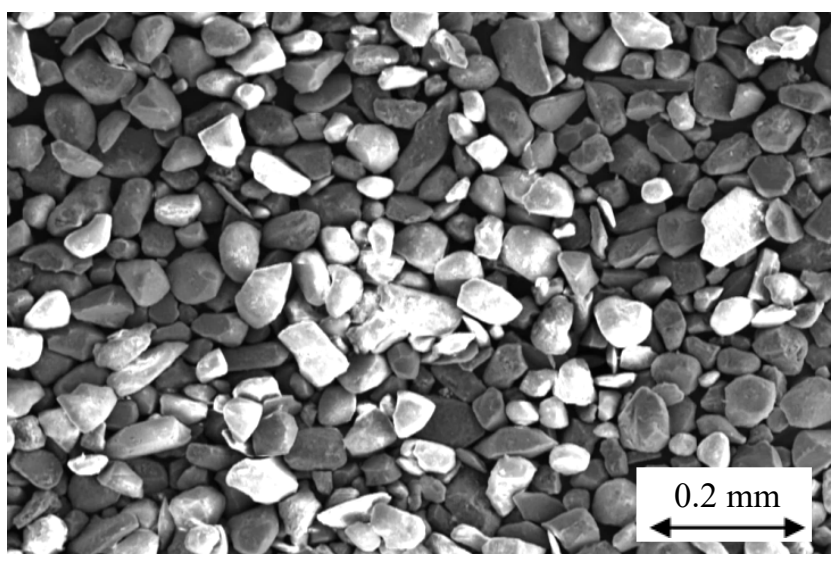

(c) Sample II: Sieved grains from Namibia with a diameter between $0.5 \mathrm{~mm}$ and $1.0 \mathrm{~mm}$.
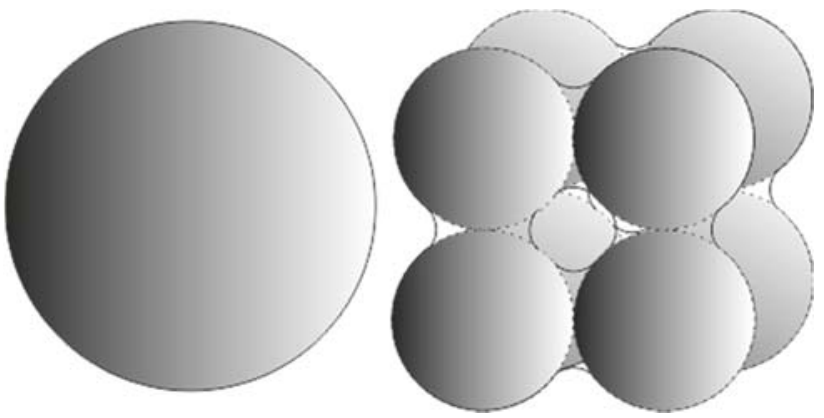

Fig. 4: Concept model. Comparison of a round shaped single grain with a combination of grains. (Graphic: F. Neumann)

The process occurs below the melting point meaning that the crystalline structure of grains is kept and amorphous states are avoided.

In Figure 5, untreated and sintered samples from two different sites in Namibia are compared. Sample I contains flaky, elongated angular grains (a) whereas sample II contains more equant and rounded grains (c) which may have led to the less porous sintered aggregate (d) compared to the porous structure from sintered sample I (b).

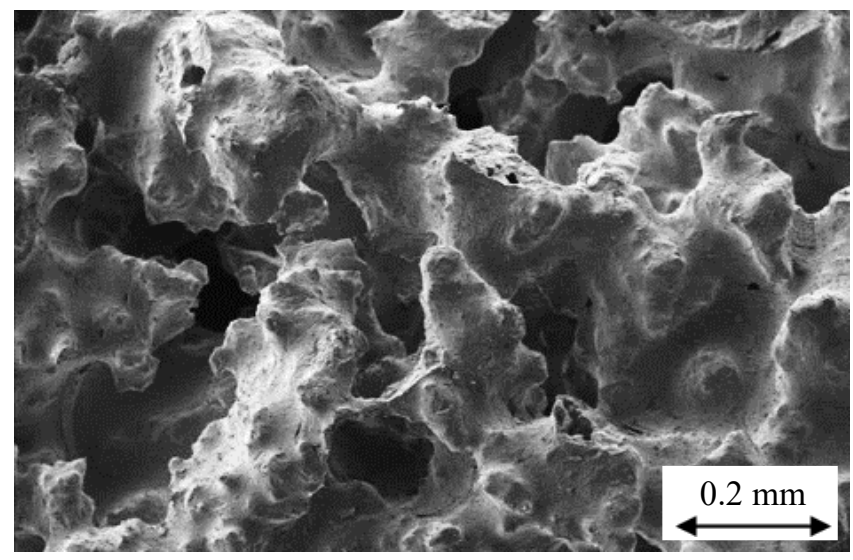

(b) Sample I: Sintered product from Namibia.

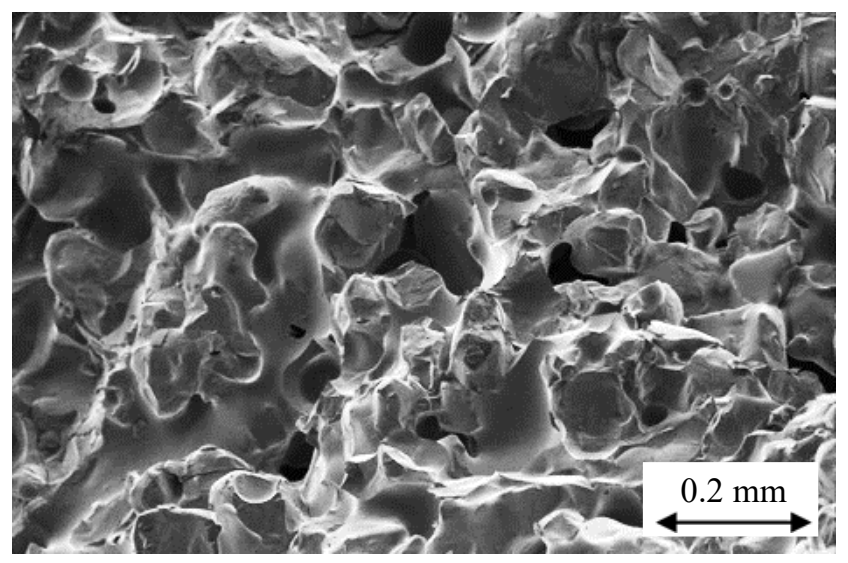

(d) Sample II: Sintered product from Namibia.

Fig. 5: ESEM analysis of different desert sand samples from Namibia. (Photos: Simone Hempel, TU Dresden) 
To proof the concept, desert sand samples were gathered and analysed by grading curve, chemical composition, melting point and $\mathrm{pH}$ value. The grading curves of unsintered samples from Algeria, Libya and Namibia are given in Figure 6 and are compared with a standard grading curve B 63 according to the German standard DIN 1045-2 [22].

The preliminary tests were conducted with grain size fractions passing the $100 \mu \mathrm{m}$ sieve. The chemical analysis was conducted to predict the melting point and to ensure that a protective atmosphere while processing is unnecessary (Table 1). Then the melting point was examined via a differential calorimetry scan (DSC) analysis. From all samples, only the ones from Namibia could be analysed due to the maximum operational temperature of $1500{ }^{\circ} \mathrm{C}$ of the DCS device. Taking the chemical composition and the melting point into account, the parameters for the sintering process were determined to $1250{ }^{\circ} \mathrm{C}$ and one hour under atmospheric pressure without any protective inert gases.

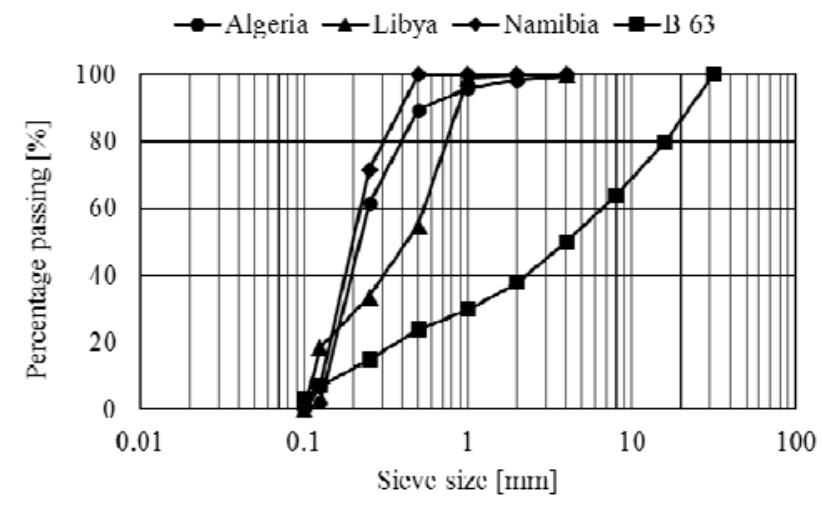

Fig. 6: Desert sand grain size distribution depending on their origin compared to standard grading curve B 63 .

(Sieve analysis by Simone Hempel, TU Dresden)

After the sintering process, the chemical composition and $\mathrm{pH}$ value from produced grains were analysed again to compare them with those from the untreated material.
Identified elements and the $\mathrm{pH}$ value from raw material grains (a), sintered grains (b) and a reference are compared in Table 1. The reference grain $(\mathrm{R})$ is an unsintered dune sand from the Kharga Oasis in Egypt [8].

Table 1: EDX analysis of sintered and unsintered samples from site I and II in Namibia including pH value comparison. (EDX analysis by Simone Hempel, Institute for Construction Materials and Michal Pejko, Institute of Manufacturing Science and Engineering, both TU Dresden)

\begin{tabular}{|l|l|l|l|l|l|l|l|l|}
\hline \multirow{2}{*}{ No. } & \multicolumn{7}{|c|}{ Elements [Atomic \%] } & \multirow{2}{*}{ (A } \\
& $\mathbf{O}$ & $\mathbf{A l}$ & $\mathbf{S i}$ & $\mathbf{S}$ & $\mathbf{K}$ & $\mathbf{C a}$ & $\mathbf{F e}$ & \\
\hline $\mathrm{Ia}$ & 52.6 & 11.0 & 24.2 & - & 3.1 & 1.3 & 3.6 & 5.7 \\
\hline $\mathrm{Ib}$ & 58.9 & 7.0 & 20.4 & - & 4.0 & 0.3 & 2.0 & 9.0 \\
\hline $\mathrm{IIa}$ & 58.8 & 1.5 & 4.6 & 13.0 & 0.5 & 19.6 & 1.0 & 8.1 \\
\hline $\mathrm{IIb}$ & 53.8 & 1.8 & 11.0 & na & 0.1 & 28.1 & 1.4 & 11.5 \\
\hline $\mathrm{R}$ & 51.6 & 5.16 & 40.3 & - & 0.1 & 0.7 & 0.8 & 7.5 \\
\hline
\end{tabular}

\section{Summary}

The Technische Universität Dresden has successfully tested a process, with which different types of desert sand were sintered to produce aggregates. The production of aggregates with varying but distinct grain sizes allows the entire substitution of conventional aggregates with those made from desert sand. Within preliminary tests, the chemical composition of different desert sands was observed via SEM micrograph and EDX analysis before and after the sinter process. It was found, that the $\mathrm{pH}$ value of sieved, cleaned and dried samples has changed from acidic to neutral or even alkaline. The process of sintering in combination with the chemical composition of different desert sands affects the porosity. In general, desert sand can be used as a substitute for fine aggregates. The produced aggregates with different porous structures are shown in Figure 7.

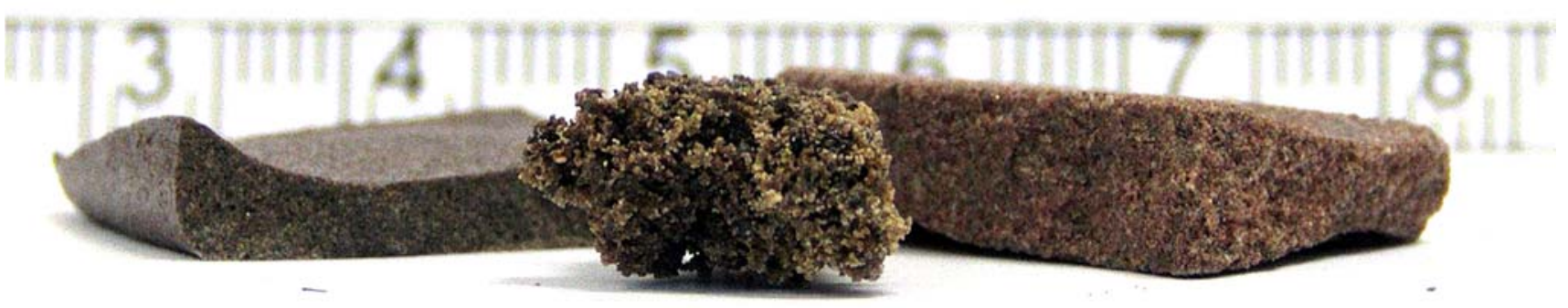

Fig. 7: Sintered aggregates produced from desert sand by TU Dresden.

(Photo: F. Neumann)

\section{Outlook}

Based on the presented, first positive results, the Technische Universität Dresden and the German Aerospace Centre (DLR) want to conduct a research project along with participating partners from Argentina, Brazil, Chile and Portugal taking into account the method of physical transformation of sand, patented by TU Dresden. Due to the high energy consumption of the sintering process, the project focuses on a solar sintering technology provided by the DLR. In the project, the partners want to focus firstly on desert sand deposit evaluation and analysis of mono- and multimodal grain sintering. Afterwards, a solar based sintering technology has to be developed. Concrete and mortar development, feasible alternative concrete made materials, developmental and social and techno-economic studies are also conducted. 


\section{References}

1. Weimar Institute of Applied Construction Research: http://www.iab-weimar.de/en/

termine? view $=$ article $\& \mathrm{id}=206$, access on 19.05.2017.

2. O. S. Kaiser, O. Krauss: Kurzanalyse Nr. 12: Systematische Ansätze zur Steigerung der Ressourceneffizienz im Bauwesen. VDI Zentrum Ressourceneffizienz GmbH, (2015).

3. WeltN24 GmbH: Die lebensnotwendige Jagt nach mehr Sand. https://www.welt.de/wirtschaft/webwelt/ article127216019/Die-lebensnotwendige-Jagd-nachmehr-Sand.html, (2014), access on 19.05.2017.

4. P. Peduzzi: Sand, rarer than one thinks. United Nations Environment Programme, (2014).

5. J. Stark, B. Wicht: Dauerhaftigkeit von Beton. Springer-Verlag Berlin Heidelberg (2013).

6. I.-S. Yoon, T. Saeki, S.-S. Park: Chloride ions adsorption and desorption in Pore Solution with various $\mathrm{pH}$ values. Second International Conference on Microstructural-related Durability of Cementitious Composites, Amsterdam (2012).

7. U. Dahme: Chlorid in karbonatisierendem Beton. $\mathrm{PhD}$ thesis. University Duisburg-Essen, (2006).

8. E.-S. S. A. Seif.: Performance of Cement Mortar Made with Fine Aggregates of Dune Sand, Kharga Oasis, Western Desert, Egypt: An Experimental Study. Jordan Journal of Civil Engineering, 7 (2013), P. 270-284.

9. F. J. Luo, et al.: Effect of very fine particles on workability and strength of concrete made with dune sand. Construction and Building Materials 47 (2013), P. 131-137.

10. A.S. Al-Harthy, et al.: The properties of concrete made with fine dune sand. Construction and Building Materials 21 (2007), P. 1803-1808.

11. A. Rmili, et al.: Incorporation of crushed sands and Tunisian desert sands in the composition of selfcompacting concretes Part II: SCC fresh and hardened states characteristics. International Journal of Concrete Structures and Materials 3 (2009), P. 1114.

12. Schladitz, F.; Tietze, M.; Lieboldt, M.; Curbach, M.: Carbon and Concrete - The Future of Construction? Bridges and Structures Sustainability - Seeking Intelligent Solutions - Proc. of IABSE Conference, 8.-11.5.2016 in Guangzhou (2016), P. 240/241.

13. Brameshuber, W. (Ed.): Report rep036 : Textile Reinforced Concrete - State-of-the-Art Report of RILEM TC 201-TRC. Bagneux: RILEM Publ., 2006.
14. T. C. Triantafillou: Textile Fibre Composites in Civil Engineering. Woodhead Publishing (2016).

15. D. Behnisch, J. Ikic: Verfahren zur Herstellung eines, zur Betonherstellung oder als Schüttgut zur Neulandgewinnung geeigneten, Sandes. Patent DE 10 2014006942 B3, (2015).

16. D. Behnisch, J. Ikic: Method and device for producing artificial crushed sand by means of a thermal treatment using sand in the form of fine sand $\left(f_{S} / f_{s} a\right)$ and/or round sand as the starting material. Patent WO 2015/172765 A1, (2015).

17. E. Rabe: Formkörper auf der Basis von Quarzsand, ihre Herstellung und Verwendung sowie Vorrichtung zur Durchführung des Verfahrens. Patent DE 3248537 A1, (1984).

18. G. Heiken, et. al.: Lunarsourcebook - a user's guide to the moon. Cambridge University Press (1991).

19. W. D. Carrier: Particle size distribution of lunar soil. Journal of Geotechnical and Geoenvironmental Engineering 129 (2003), P. 956-595.

20. S. Willhelm, M. Curbach: Review of possible mineral materials and production of techniques for building material on the moon. Structural Concrete 15 (2014), P. 419-428.

21. F. Neumann, M. Curbach: Verfahren und Vorrichtung zur thermischen Behandlung von Sand. Patent WO 2017016550 A1, (2015).

22. DIN 1045-2: Concrete, reinforced and prestressed concrete structures - Part 2: Concrete - Specification, properties, production and conformity Application rules for DIN EN 206-1 (2008).

The authors like to thank all colleagues, especially Simone Hempel, Michal Pejko, Johannes Trapp (TU Dresden) and Karin Weimann (BAM Berlin) for supporting the idea with trial testing.

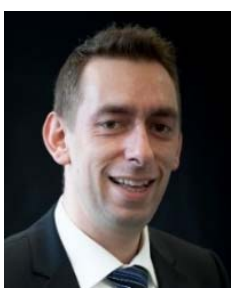

Dipl.-Ing. (FH)

Frank Neumann

Research associate

Institute of Concrete Structures

Technische Universität Dresden

01062 Dresden, Germany

frank.neumann1@tu-dresden.de

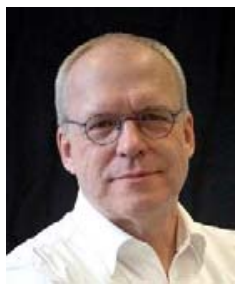

Prof. Dr.-Ing. Dr.-Ing. E.h.

Manfred Curbach

Professor, institute's director

Institute of Concrete Structures

Technische Universität Dresden 01062 Dresden, Germany 